\title{
The prognostic value of transesophageal echocardiography after transvenous lead extraction: landscape after battle
}

\author{
Dorota Nowosielecka ${ }^{1}$, Wojciech Jacheć ${ }^{2}$, Anna Polewczyk ${ }^{3,4}$, Andrzej Kleinrok ${ }^{1,5}$, Lukasz Tułecki ${ }^{6}$, \\ Andrzej Kutarski ${ }^{7}$ \\ ${ }^{1}$ Department of Cardiology, The Pope John Paul II Province Hospital of Zamość Poland; ${ }^{2}$ 2nd Department of Cardiology, Faculty of Medical \\ Sciences, Medical University of Silesia, Zabrze, Poland; ${ }^{3}$ Collegium Medicum, The Jan Kochanowski University, Kielce, Poland; ${ }^{4}$ Department of \\ Cardiac Surgery, Świętokrzyskie Cardiology Center, Kielce, Poland; ${ }^{5}$ Medical College, Department of Physiotherapy, University of Information \\ Technology and Management, Rzeszów, Poland; ${ }^{6}$ Department of Cardiac Surgery, The Pope John Paul II Province Hospital of Zamość Poland; \\ ${ }^{7}$ Department of Cardiology, Medical University, Lublin, Poland \\ Contributions: (I) Conception and design: D Nowosielecka; (II) Administrative support: A Polewczyk; (III) Provision of study materials or patients: All \\ authors; (IV) Collection and assembly of data: $€$ Tułecki, A Kleinrok, A Kutarski; (V) Data analysis and interpretation: D Nowosielecka, W Jacheć, A \\ Polewczyk; (VI) Manuscript writing: All authors; (VII) Final approval of manuscript: All authors. \\ Correspondence to: Anna Polewczyk, MD, PhD. Swietokrzyskie Cardiology Center, 45, Grunwaldzka St. 25-736 Kielce, Poland. \\ Email: annapolewczyk@wp.pl.
}

Background: In patients undergoing transvenous lead extraction (TLE) transesophageal echocardiography (TEE) provide valuable information after procedure.

Methods: We analyzed data from 936 TEE performed in patients undergoing TLE between 2015 and 2019 (mean follow-up $566.23 \pm 224.47$ days) and assessed the role of echocardiographic phenomena after procedure.

Results: Increment in tricuspid regurgitation (TR) was observed in $9 \%$ of patients after TLE. Factors increasing the risk of TR were: binding sites between lead and right ventricle (RV) (OR: 5.429), tricuspid valve (TV) (OR: 3.42), superior vena cava (SVC) (OR: 3.30) and lead-to-lead adhesions (OR: 2.88). Predisposing factors of residual structures after TLE were: asymptomatic masses on the leads (AMEL) (OR: 1.68), binding sites between SVC and cardiac structures (OR: 1.72), and multiple leads (OR: 1.30). Probability of vegetation remnants increased in the presence of abandoned leads (OR: 7.91). The risk factors of tamponade were: dwell time of the oldest lead (OR: 1.17), lead-to-lead adhesion (OR: 22.47), binding sites between lead and TV (OR: 6.08), RA (OR: 11.50), SVC (OR: 4.47), higher LVEF (OR: 2.35; P=0.006), female gender (OR: 5.43), multiple leads (OR: 2.11), looped leads (OR: 4.90) and AMEL (OR: 6.42). The risk of lead fracture was increased by: lead-to-lead adhesion (OR: 5.69), fibrosis binding the lead to RV (OR: 5.16), RA (OR: 2.39) and dwell time of the oldest lead (OR: 1.068). The mortality rate was $11.97 \%$ during follow-up. The risk of death was increased by: severe TR and vegetation remnants.

Conclusions: The most important phenomena evaluated after TLE are: tricuspid valve function, residual fibrosis and vegetation remnants, progression of pericardial effusion and retained lead fragments. Postoperative TEE provides information about the results of TLE and helps establish further management.

Keywords: Transvenous lead extraction (TLE); transesophageal echocardiography (TEE); lead extraction-related tricuspid valve damage; vegetation remnants; retained lead fragments; connective tissue scar

Submitted Oct 23, 2020. Accepted for publication Dec 20, 2020.

doi: $10.21037 / \mathrm{cdt}-20-871$

View this article at: http://dx.doi.org/10.21037/cdt-20-871 


\section{Introduction}

Transvenous lead extraction (TLE) is a first-line strategy for the treatment of complications related to cardiac implantable electronic devices (CIED). The procedure, performed in accordance with the commonly accepted standards of clinical practice is relatively safe; the rate of major complications ranges from $0.9 \%$ to $4.0 \%$, whereas a death rate is low i.e., $0.2-0.4 \%(1-3)$. The European Heart Rhythm Association (EHRA) and the Heart Rhythm Society (HRS) advocate continuous transesophageal echocardiography (TEE) monitoring or intracardiac echocardiography (ICE) to improve procedural safety (1-3). The available evidence shows the increasing role of echocardiography during TLE. Apart from evaluating changes related to chronically indwelling endocardial leads and their impact on the course of TLE, monitoring of lead extraction and the extractor's manipulations within the heart walls to explain possible hemodynamic instability (4-9), echocardiographic assessment after the procedure ("landscape after battle") is a very important component of effective care management.

We present the following article in accordance with the MDAR reporting checklist (available at http://dx.doi. org/10.21037/cdt-20-871).

\section{Methods}

\section{Study group}

In this study, a total of 1,026 lead extractions were performed at a single high volume center from June 2015 to October 2019. Of these, 936 procedures were guided by TEE before, during and after the extraction. The indications for TLE included infectious and non-infectious complications associated with cardiac implantable electronic devices (CIED). The infectious complications were pocket infection and/or lead-related infective endocarditis (LRIE). Non-infectious indications included mechanical lead damage (electrical failure), lead dysfunction (exit/entry block, dislodgement, extracardiac pacing), perforation, the need to change the pacing mode, and the need to remove leads with immediate or potential threat if left in place.

The clinical characteristics of the patients before TLE were described in detail in previous publications $(4,5)$.

\section{Lead extraction procedure}

All TLE procedures were performed in a hybrid operating room or an operating room using mechanical systems such as polypropylene Byrd dilators (Cook ${ }^{\circledR}$ Medical, Leechburg, PA, USA). The use of mechanical, cutting, and rotational force of the catheters and simple traction permitted complete extraction of a decided majority of leads. In case of difficulties second-line equipment was used i.e., Evolution (Cook), TightRail (Spectranetix) and lasso catheters, etc. Laser energy was not used. The organizational aspects of lead extraction procedure (venue, team) were described in detail in previous publications $(4,5)$.

\section{Echocardiographic study}

TEE was performed using Philips iE33 or GE Vivid S 70 machines equipped with $\mathrm{X} 7-2 \mathrm{t}$ Live $3 \mathrm{D}$ or $6 \mathrm{VT}-\mathrm{D}$ probes with the recordings being archived. Leads were evaluated in the mid-esophageal, inferior esophageal and modified transgastric views to visualize the right heart chambers and the tricuspid valve. In order to obtain complete visualization of the anatomical structures and assessment of the course of the lead non-standard imaging planes were sometimes required. The projections and consecutive stages of echocardiographic monitoring were described in detail in previous publications $(4,5)$.

\section{Areas of interest}

The relationship between CIED-associated clinical and procedural variables, and echocardiographic findings after TLE was analyzed. The following clinical factors were taken into account: demographics, left ventricular ejection fraction (LVEF), heart failure according to NYHA, renal failure, anticoagulation therapy and Charlson Comorbidity Index. Analysis of procedural factors included indications for TLE, lead implant duration, number and type of leads, procedure duration, TLE efficacy and periprocedural complications.

The analysis of some parameters after TLE required comparison with the phenomena assessed before and during the procedure. Echocardiographic phenomena assessed preand intra-procedure have already been presented by the author in previous publications $(4,5)$.

Echocardiographic assessment after TLE included monitoring of the patient for signs and symptoms of cardiac tamponade, observation of vegetation dislodgement and visualization of their remnants in cardiac cavities, and detection of residual fibrosis after lead extraction. Fibrosis was defined as immobile masses binding the lead to the 
vein or heart wall most frequently represent a sign of preexisting asymptomatic inflammatory response triggered by the endocardial lead (foreign body reaction). The term encompassed also segmental lead-to-lead adhesion (two or three leads) moving along together with the cardiac walls.

Echocardiographic evaluation after TLE included also tricuspid valve function by comparing the degree of tricuspid regurgitation (TR) before and after TLE. Particular attention was focused on reduction in TR after TLE in patients with lead-dependent tricuspid dysfunction (LDTD).

We also searched for possible metal tips of the lead or silicon tube fragments left in situ.

Additionally, we evaluated the effect of all these factors on prognosis in 2-year follow-up. The exact date of death was obtained from the patient's medical records, relatives, or a national identity database.

\section{Ethical statement}

The study was conducted in accordance with the Declaration of Helsinki (as revised in 2013). The study was approved by institutional Bioethics Committee at Regional Physicians Chamber in Lublin (no. 288/2018/KB/VII). And informed consent was taken from all the patients

\section{Statistical analysis}

Despite nonparametric distribution of some of the continuous variables, for uniformity, they are presented as mean \pm standard deviation and analyzed using the Wilcoxon signed rank test and the Mann-Whitney U test. The categorical variables are presented as number and percentage and compared using the $\mathrm{Chi}^{2}$ test with Yates correction. The relationships between clinical and procedural factors, fibrous tissue changes, CIED-related variables, and the results of postoperative TEE with respect to TV function, vegetations, additional fibrous masses, retained lead fragments and fluid accumulation in the pericardial space were analyzed using univariate and multivariate regression analysis. All statistically significant $(\mathrm{P}<0.05)$ variables in univariate analysis were included into a multivariate model. Because of a small sample size, the incidence of tamponade was analyzed only in univariate analysis.

The impact of TEE findings on survival at 2-year followup was evaluated using univariate and multivariate Cox logistic regression. All statistically significant $(\mathrm{P}<0.05)$ variables in univariate analysis were included into a multivariate model. For selected parameters (vegetations, grade of TR after TLE: 0-II vs. III-IV) Kaplan-Meier survival curves were defined, and their course was evaluated with $\log$ rank test. A two-tailed $\mathrm{P}$ value $<0.05$ was considered statistically significant. The lack of statistical significance was indicated as NS (non-significant). Statistical analysis was performed with STATISTICA 13.0 (TIBCO Software Inc. Krakow, Poland).

\section{Results}

\section{Clinical characteristics of the study group and procedure- related information (Table 1)}

TEE after TLE was performed in 936 patients (including 355 women; $37.92 \%$ ), with a mean age of $67.08 \pm 14.50$. Patients in NYHA class III and IV were a minority (148; $15.81 \%)$. There were $230(24.89 \%)$ patients with chronic renal failure, and 389 (41.56\%) receiving chronic anticoagulation therapy. The mean Charlson Comorbidity Index was $4.886 \pm 3.76$. Infection was an indication for TLE in $22.33 \%$ of patients, including $151(16.13 \%)$ patients with LRIE, whereas $58(6.20 \%)$ patients had pocket infection. Other indications, most common in this study population (77.67\%) included lead dysfunction, the need to regain venous access and to change pacing mode, LDTD, need for MRI or radiotherapy. The number of leads in the patient before TLE was $1.83 \pm 0.63$ on average, dwell time of the oldest lead in the patient $115.84 \pm 77.63$ months. High voltage (HV) leads were inserted in 296 (31.62\%) patients, coronary sinus (CS) lead in $153(16.35 \%)$ patients. The mean duration of the procedure measured from dissection of the first lead to removal of the last one (sheath to sheath time) was $15.93 \pm 25.56 \mathrm{~min}$ on average. There were 18 (1.92\%) major complications, including 12 (1.28\%) cases of bleeding into the pericardial space with the signs of tamponade, $6(0.64 \%)$ cases with severe tricuspid valve damage. There were no deaths related to TLE. Complete procedural success was achieved in $97.97 \%$, complete clinical success in $97.86 \%$ (Table 1). Follow-up after TLE was 2 years, $556.20 \pm 224.50$ days on average (min. 2, max, 700 days), there were 112 (11.97\%) deaths.

A comparative analysis of echocardiographic phenomena occurring before and after TLE was presented in Appendix 1 . 
Table 1 Patient characteristics, system, and procedure information

\begin{tabular}{|c|c|}
\hline Parameters & Values \\
\hline \multicolumn{2}{|l|}{ Patient characteristics } \\
\hline Number of patients, n (\%) & $936(100.000)$ \\
\hline Patient age during TLE (years), mean \pm SD & $67.081 \pm 14.500$ \\
\hline Gender, Female patients, n (\%) & 355 (37.927) \\
\hline NYHA III \& IV (\%), n (\%) & $148(15.812)$ \\
\hline LVEF [\%], mean \pm SD & $47.885 \pm 15.557$ \\
\hline LVEF normal $\geq 50 \%, n(\%)$ & $539(57.585)$ \\
\hline LVEF lowered <50\%, n (\%) & $397(42.415)$ \\
\hline Renal failure (any), n (\%) & $230(24.892)$ \\
\hline Long-term anticoagulation, $\mathrm{n}(\%)$ & $389(41.560)$ \\
\hline Charlson's Comorbidity Index, mean \pm SD & $4.886 \pm 3.764$ \\
\hline \multicolumn{2}{|l|}{ TLE indications } \\
\hline LRIE with or without pocket infection n (\%) & $151(16.132)$ \\
\hline Local (pocket) infection (only) n (\%) & $58(6.196)$ \\
\hline Non-infectious indications n (\%) & $727(77.671)$ \\
\hline \multicolumn{2}{|l|}{ System and history of pacing } \\
\hline $\begin{array}{l}\text { Dwell time of the oldest lead (in months) in } \\
\text { the patient before TLE, mean } \pm S D\end{array}$ & $115.843 \pm 77.633$ \\
\hline $\begin{array}{l}\text { Mean implant duration (in months) before } \\
\text { TLE, mean } \pm S D\end{array}$ & $108.215 \pm 69.660$ \\
\hline $\begin{array}{l}\text { Cumulative dwell time of extracted lead (in } \\
\text { years) before TLE, mean } \pm S D\end{array}$ & $17.843 \pm 14.530$ \\
\hline $\begin{array}{l}\text { Number of leads in the system before TLE, } \\
\text { mean } \pm S D\end{array}$ & $1.834 \pm 0.629$ \\
\hline Abandoned leads before TLE, n (\%) & $86(9.188)$ \\
\hline HV lead before TLE, n (\%) & $296(31.624)$ \\
\hline CS lead before TLE, n (\%) & $153(16.346)$ \\
\hline $\begin{array}{l}\text { Number of procedures before lead extrac- } \\
\text { tion (SD) }\end{array}$ & $1.837 \pm 0.990$ \\
\hline \multicolumn{2}{|l|}{ TLE procedure efficacy and outcomes } \\
\hline $\begin{array}{l}\text { Procedure duration (in minutes) (sheath to } \\
\text { sheath), mean } \pm S D\end{array}$ & $15.931 \pm 25.558$ \\
\hline Technical problems during TLE (any), n (\%) & $231(24.679)$ \\
\hline \multicolumn{2}{|l|}{ TLE efficacy and complications } \\
\hline Major complications (any), n (\%) & $18(1.923)$ \\
\hline Complete clinical success, n (\%) & $916(97.863)$ \\
\hline Complete procedural success, n (\%) & 917 (97.970) \\
\hline
\end{tabular}

Factors influencing functional and morphological changes occurring during TLE

\section{Results of univariate and multivariable regression analysis (Table 2) \\ Factors influencing function of the tricuspid valve}

Fibrosis binding leads to tricuspid apparatus (OR: 0.33; $\mathrm{P}<0.001)$, lead colliding with the tricuspid valve apparatus (OR: 0.39; $\mathrm{P}=0.04$ ) and fibrosis binding leads to the $\mathrm{RV}$ wall (OR: 0.49; $\mathrm{P}=0.014)$ were the factors that determined valve function after TLE. The likelihood of TR worsening by $\geq 2$ grades was significantly higher in patients with adhesive interaction between leads and endocardial surface of the RV wall (OR: 5.43; $\mathrm{P}<0.001)$, tricuspid valve apparatus (OR: 3.42; $\mathrm{P}=0.009)$, superior vena cava (SVC) (OR: 3.30; $\mathrm{P}=0.017$ ) as well as lead-to-lead adhesions (OR: 2.88; $\mathrm{P}=0.025)$. TR worsening by one grade was significantly related only to binding sites between lead and RV (OR: 4.45; $\mathrm{P}=0.001)$. The factors that decreased the likelihood of valve damage were excessive lead loops (OR: 0.07; $\mathrm{P}=0.041)$ and chronic atrial fibrillation (OR: 0.22; $\mathrm{P}=0.046)$. Improvement of $\mathrm{TV}$ function was more frequently observed in women (OR: 1.66; $\mathrm{P}=0.027$ ), in patients with noninfectious indications for TLE (OR: 2.40; $\mathrm{P}=0.008$ ) and when the lead was adherent to the RA wall (OR: 2.08; $\mathrm{P}=0.028)$. Chances for TV improvement were smaller (OR: $0.85 ; \mathrm{P}=0.031)$ in patients with low LVEF (Table 2).

\section{Factors influencing the ultimate fate of vegetations}

The only factor that influenced the fate of vegetations were redundant leads. In these patients, vegetation remnants were significantly more frequent $(\mathrm{OR}: 7.91 ; \mathrm{P}=0.011)$ and consequently, the vegetations less often "disappeared" (broke into pieces and migrated to the pulmonary circulation) during TLE (OR: 0.13; $\mathrm{P}=0.012$ ) (Table 2).

\section{Factors influencing the incidence of residual fibrosis}

The factors that increased the likelihood of residual fibrosis after TLE included asymptomatic masses on the leads (AMEL) (connective tissue surrounding the lead, lead thickening, thrombus attached to the lead, vegetation-like masses) (OR: 1.68; $\mathrm{P}=0.001)$, binding sites between leads and SVC and cardiac anatomical structures (OR: 1.72; $\mathrm{P}=0.001$ ), and multiple extracted leads (OR: $1.30 ; \mathrm{P}=0.034$ ).

The study did not identify the factors that would decrease the likelihood of residual fibrosis after TLE (Table 2). Factors influencing bleeding into the pericardial space The most significant risk factors for acute tamponade were dwell time of the oldest lead (each year) (OR: 1.17; 
Table 2 Factors influencing functional and morphological changes during TLE: results of univariate and multivariate regression analysis

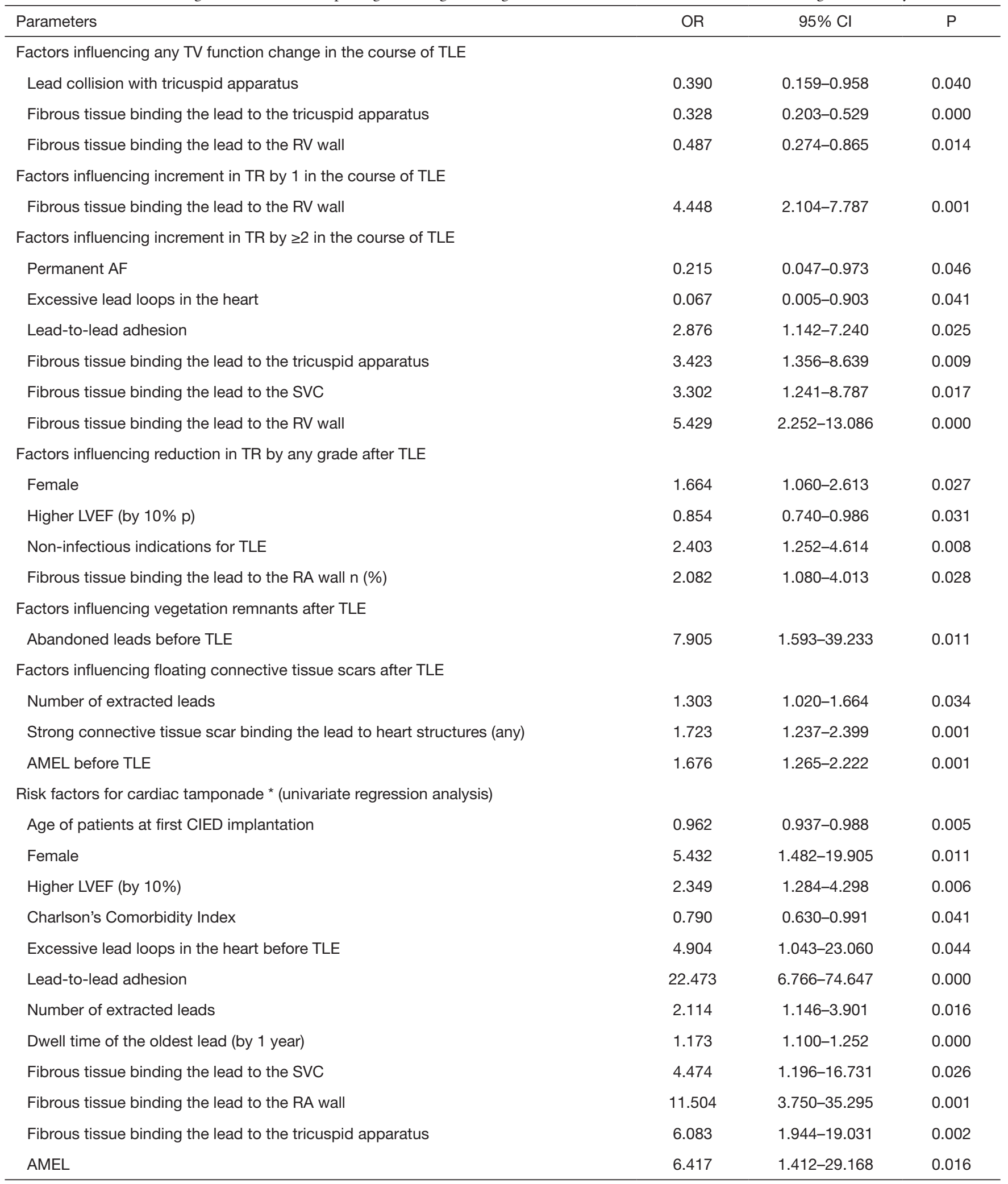

Table 2 (continued) 
Table 2 (continued)

\begin{tabular}{llc}
\hline Parameters & OR & 95\% Cl \\
\hline Pericardium: fluid without hemodynamic consequences & & P \\
Dwell time of the oldest lead (by 1 year) & 1.087 & $1.017-1.162$ \\
Factors affecting lead fracture & 5.686 & $2.635-12.271$ \\
Lead-to-lead adhesion & 1.068 & $1.014-1.125$ \\
Dwell time of the oldest lead (by 1 year) & 2.393 & 0.000 \\
Fibrous tissue binding the lead to the RA wall & 5.157 & 0.013 \\
Fibrous tissue binding the lead to the RV wall & $2.613-10.176$ & 0.000 \\
\hline
\end{tabular}

$\mathrm{P}<0.001$ ), lead-to-lead adhesion (OR: 22.47; $\mathrm{P}<0.001$ ), binding sites between leads and TV (OR: 6.08; $\mathrm{P}=0.002)$, RA (OR: 11.50; $\mathrm{P}=0.001)$, SVC (OR: 4.47; $\mathrm{P}=0.026)$ and higher LVEF (for each 10\%) (OR: 2.35; $\mathrm{P}=0.006$ ). Moreover, the risk of tamponade increased in relation with female gender (OR: 5.43; $\mathrm{P}=0.011$ ), multiple extracted leads (OR: 2.11; $\mathrm{P}=0.016$ ), excessive lead loops (OR: 4.90; $\mathrm{P}=0.044)$ and AMEL (OR: 6.417; $\mathrm{P}=0.016$ ). Older age at CIED implantation (OR: 0.96; $\mathrm{P}=0.005$ ) and accompanying diseases expressed as higher Charlson Comorbidity Index (OR: $0.79 ; \mathrm{P}=0.041$ ) were found to decrease the probability of bleeding into the pericardial space.

The sole factor increasing the risk of asymptomatic/ hemodynamically stable hemopericardium was dwell time of the oldest lead (OR: 1.09; $\mathrm{P}=0.014$ ) (Table 2).

Factors influencing lead fracture during TLE

The risk factors for lead fracture included lead-to-lead adhesion (OR: 5.69; $\mathrm{P}<0.001)$, binding sites between leads and RV (OR: 5.16; $\mathrm{P}<0.001)$, RA (OR: 2.39; $\mathrm{P}=0.042)$ and dwell time of the oldest lead (OR: 1.07; $\mathrm{P}=0.013$ ). The study did not identify the factors that would decrease the risk for lead fracture (Table 2).

\section{Effect of postoperative functional and morphological findings within the heart on 2-year survival (Table 3)}

During the mean follow-up period of $566.229 \pm 224.468$ ( 2 to 730 ) days 112 deaths were observed in the study population.

The effect of TEE variables on survival at 2-year followup was evaluated using univariate and multivariate Cox regression, of which only the presence of significant TR and vegetation remnants were of prognostic value. Mortality risk was a $45.6 \%$ (HR 1.46; 95\% CI: 1.23-1.73; $\mathrm{P}=0.001$ ) higher for each grade of regurgitation. The presence of vegetation remnants after TLE was associated with a $75.9 \%$
(HR 1.76; 95\% CI: 1.35-2.30; $\mathrm{P}=0.001$ ) higher risk of death at 2-year follow-up (Table 3).

\section{Discussion}

TEE is a very useful tool in patients undergoing transvenous leads extraction. TEE can detect adverse consequences of procedure and helps in making postoperative clinical decisions (5-9). The present study describes "landscape after battle" with TEE results being grouped into the following five areas: tricuspid valve function, residual fibrosis, the ultimate fate of vegetations, accumulation of fluid in the pericardial space and lead remnants inadvertently left in the heart.

The assessment of TV function before and after TLE is very important as the available evidence shows that severe tricuspid regurgitation is associated with a poor prognosis (10-12). Additionally, damage to the tricuspid apparatus can occur during extraction of the RV lead, most frequently due to adhesion of chronically indwelling leads to cardiac anatomical structures (including TV) (13-19) (Figure 1).

Damage to the tricuspid valve during extraction is estimated to range from $3.5 \%$ to $15 \%$, and even to $19 \%$ $(1,13-18)$. In this study clinically insignificant valve dysfunction was detected in about $9 \%$ of cases, whereas significant TV damage that caused TR worsening by 2 or 3 grades as compared to baseline (before TLE) occurred in $3.5 \%$ of patients, which is less than previously reported $(1,13-18)$. The need for surgical intervention in such cases is rare (17). Initially, $1.4 \%$ of patients were evaluated as potentially requiring surgical repair, finally valvuloplasty was performed in $8(0.9 \%)$ patients. The relatively good results in this study may be explained by a vast practical experience and continuous TEE monitoring helping warn the operator about potentially harmful situations leading to TV damage (5). The 
Table 3 The impact of functional (grade of tricuspid regurgitation or its change after TLE) and morphological changes, diagnosed by TEE during TLE on survival after TLE at 2-year follow-up: results of univariate and multivariate Cox regression analysis

\begin{tabular}{|c|c|c|c|c|c|c|}
\hline Parameters & \multicolumn{3}{|c|}{ Univariate Cox regression analysis } & \multicolumn{3}{|c|}{ Multivariate Cox regression analysis } \\
\hline Tricuspid regurgitation (after TLE) (yes/no) & 1.500 & $1.270-1.772$ & 0.001 & 1.456 & $1.227-1.727$ & 0.001 \\
\hline $\begin{array}{l}\text { Tricuspid regurgitation without change after TLE } \\
\text { (yes/no) }\end{array}$ & 0.956 & $0.604-1.512$ & 0.847 & & & \\
\hline $\begin{array}{l}\text { Tricuspid regurgitation change after TLE (+ } 2 \text { or } 3 \text { ) } \\
\text { grade }\end{array}$ & 1.097 & $0.404-2.976$ & 0.856 & & & \\
\hline $\begin{array}{l}\text { Tricuspid regurgitation change after TLE ( }-1 \text { or } 2 \\
\text { or } 3 \text { ) grade }\end{array}$ & 1.133 & $0.635-2.020$ & 0.672 & & & \\
\hline $\begin{array}{l}\text { Appearance of fluid during TLE without cardiac } \\
\text { tamponade (yes/no) }\end{array}$ & 0.968 & $0.239-3.921$ & 0.964 & & & \\
\hline Presence of vegetations after TLE (yes/no) & 1.963 & $1.523-2.529$ & 0.001 & 1.759 & $1.348-2.295$ & 0.001 \\
\hline Lead fracture during extraction (yes/no) & 1.776 & $0.927-3.402$ & 0.083 & & & \\
\hline
\end{tabular}

TEE, transesophageal echocardiography; TLE, transvenous lead extraction.

available evidence shows the following factors predisposing to TV damage: longer implant duration, pacemaker leads, patient age $\geq 75$ years, removal of $\geq 2$ leads (13) as well as female gender, use of laser catheters, the need for additional tools during TLE, vegetations attached to TV and/or leads (15,18-20). This study demonstrated that the probability of TV damage was related mainly to adhesion of leads to tricuspid valve. Binding sites between leads and RV endocardium and lead-to-lead adhesions may play an indirect role through the impact on the incompletely controlled traction during lead extraction. It may be concluded that a long lead dwell time creates conditions for the development of connective tissue and adhesion of leads to tricuspid leaflets or tendinous chords. In consequence, the technically difficult procedure of lead removal requiring the use of additional, more aggressive tools and stronger traction during the extraction increases the risk of damage. It is interesting to note that in this study chronic atrial fibrillation was associated with a lower incidence of significant TV damage. A possible explanation might be dilatation of the TV annulus due to enlargement of right heart chambers in which lead mobility is preserved, thus reducing chances for adhesion. In turn, the effect of excessive lead loops on tricuspid valve function depended on their location. Our previous study demonstrated that excessive lead loops in the TV orifice were found only in $3.7 \%$, in the $\mathrm{RV}$ in $2.99 \%$, but most often in the RA i.e., in $14.7 \%$ of cases, which usually did not affect tricuspid function (5). In this study, generally there was no significant difference in the incidence of tricuspid regurgitation before and after the procedure. Lead-unrelated TR was found in almost $42 \%$ of patients (significant TR in over $23 \%$ ), and the rates were comparable before and after TLE. At 2-year follow-up TR was found to be a significant factor worsening prognosis and causing a $45.6 \%$ increase in the risk of death for each grade of TV regurgitation (HR 1.456, 95\% CI: 1.227-1.727, $\mathrm{P}=0.001$ ) (Figure 2).

Another important issue addressed in the present study is tricuspid regurgitation induced by a right ventricular lead. LDTD is a well-known complication of CIED implantation occurring at a rate of $25 \%$ to $35 \%$ (21-26), not infrequently being a direct indication for TLE (25-27). LDTD contributes to RA and RV enlargement and increases pulmonary arterial pressure, and what is important, it is associated with higher mortality in patients having CIED. Significant TR associated with the presence 

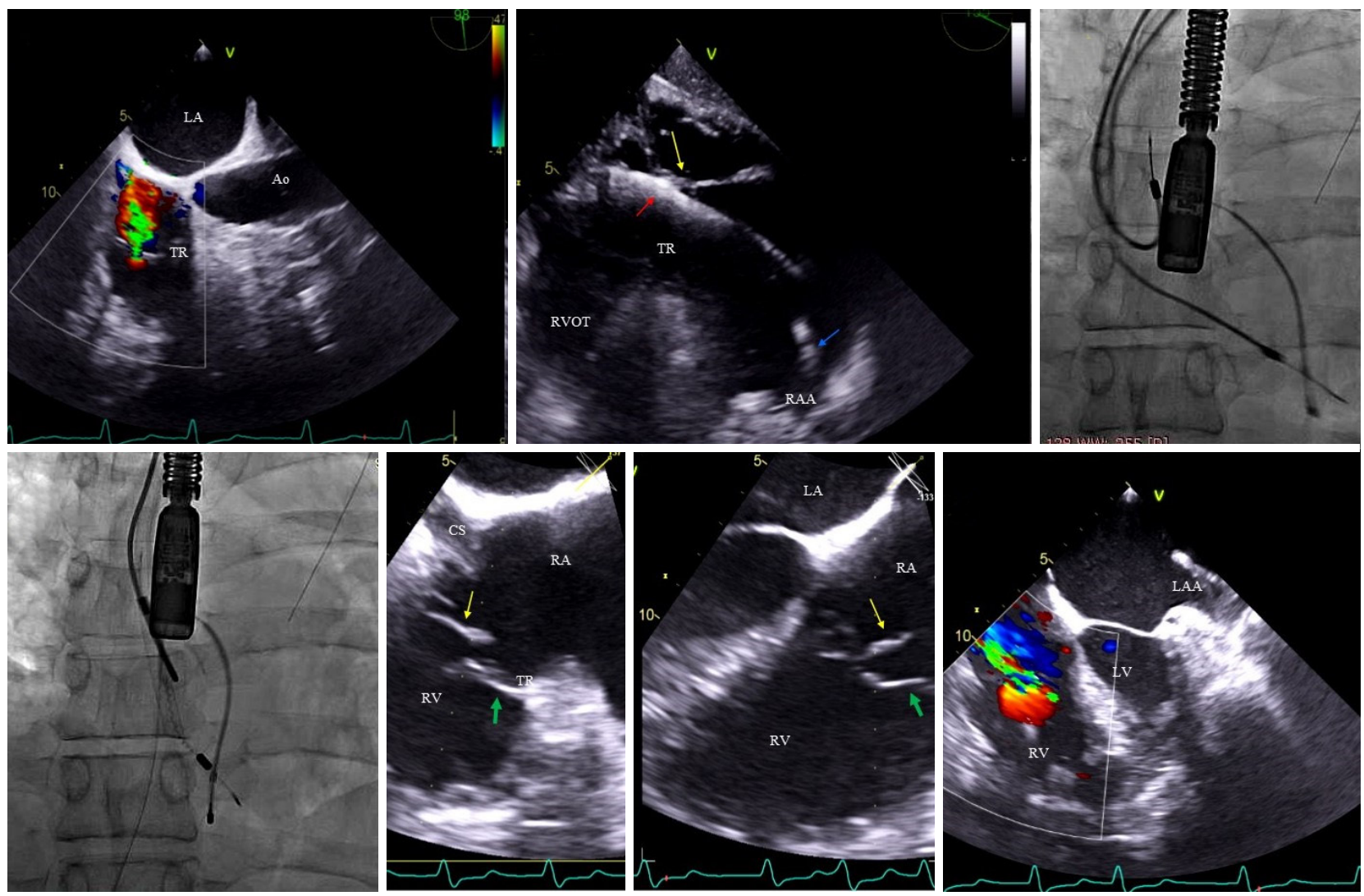

Figure 1 Damage to the tricuspid valve during TLE demonstrable by TEE. Red arrow: adhesion of the lead to the posterior leaflet (yellow arrow); green arrow: anterior leaflet; blue arrow: lead in the right atrium.

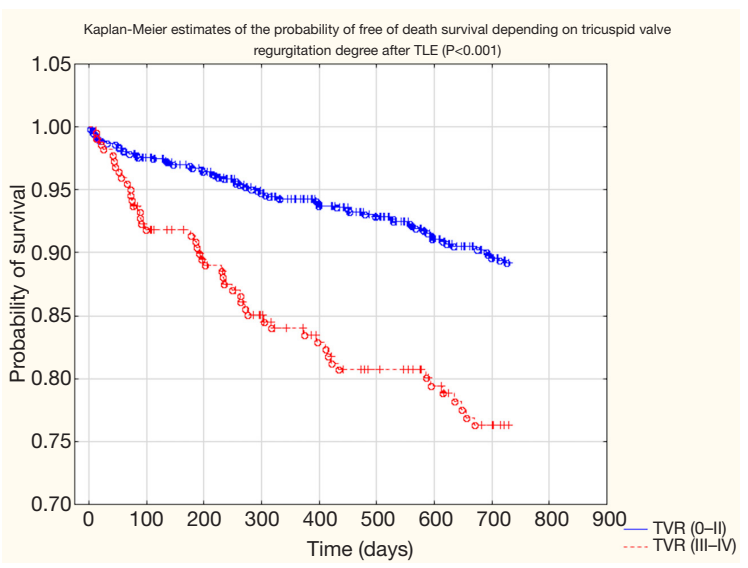

Figure 2 Kaplan-Meier estimates of the probability of free of death survival depending on the grade of tricuspid valve regurgitation after TLE. $\mathrm{P}<0.001$.

of right ventricular leads worsens long-term prognosis and is an independent risk factor for premature death (22-24). On the other hand, timely removal of the lead inducing valve dysfunction may result in valve improvement (Figure 3).

Our understanding of improvement in TR after lead removal is limited to a few reports of other investigators $(28,29)$ and our previous research $(27)$. In this study tricuspid function improved in 100 patients, including significant improvement in only 10 cases, whereas severe TR was found in $96.66 \%$ of patients with LDTD. A possible cause of low rate of improvement is too late referral for TLE in the situation when RA enlargement, TV annulus dilatation and RV remodeling in severe regurgitation (28) are too large.

Another important TEE finding that deserves attention after TLE is dislodgement of vegetations and residual fibrosis. Previous research in preoperative TTE, TEE and ICE has found movable masses attached to the leads, representing vegetations or connective tissue both in asymptomatic and symptomatic patients (30-34). Some of them may remain in cardiac cavities after TLE whereas others may emerge during lead dissection. In this study they were detected in a total of 360 (38.461\% of all) patients, 

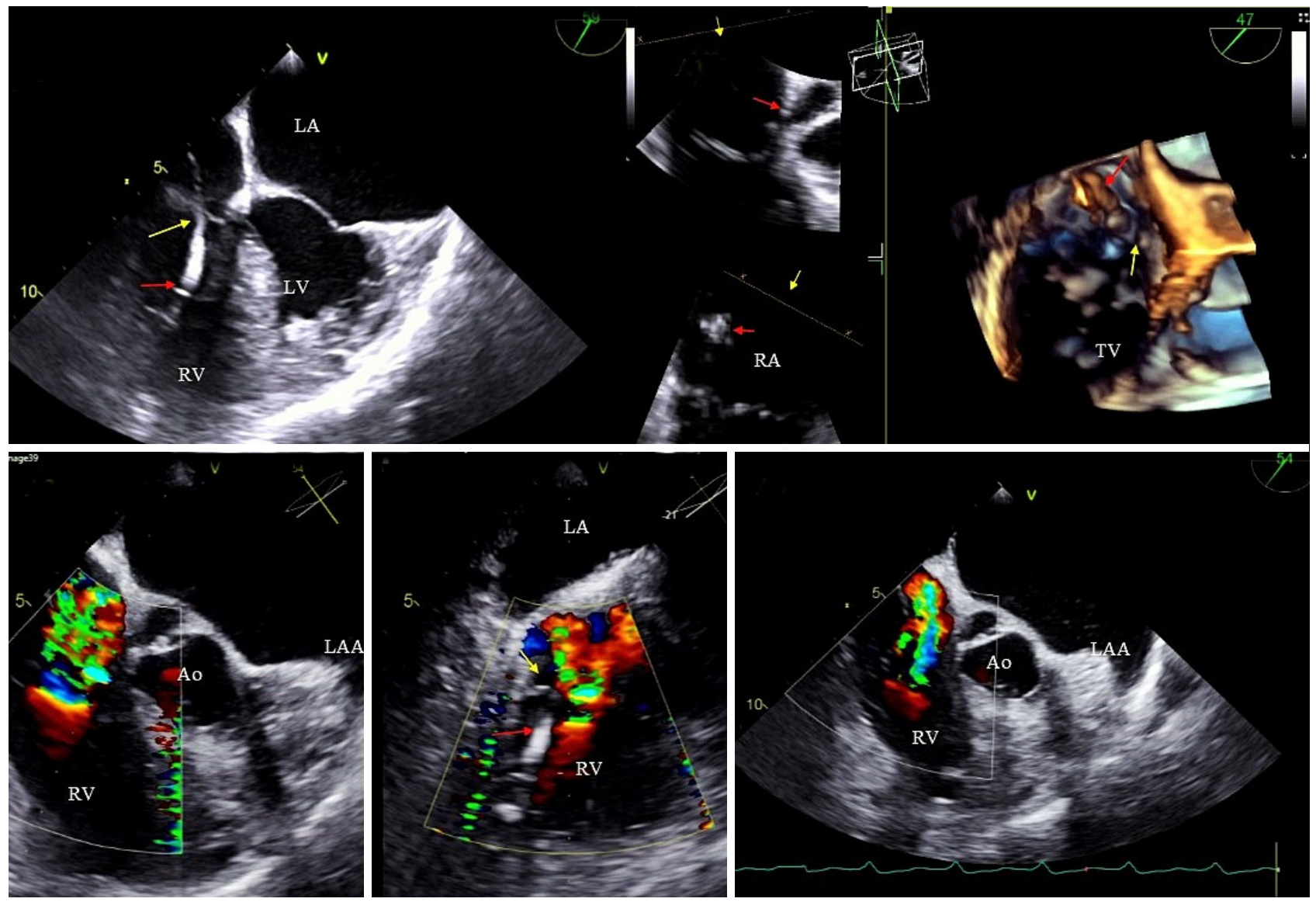

Figure 3 Improvement in TR after removal of the lead impinging on the leaflet. The arrows show the course of the lead colliding with the tricuspid valve leaflet.

including residual fibrosis in 310 patients $(33.119 \%$ of all) and vegetation remnants in 50 (5.341\% of all) patients. These additional masses detected after TLE have been referred to as ghosts (1,35-37), however the definition is not precise, as the term encompasses fragments both of connective tissue and vegetations. This phenomenon was first described in the patient undergoing TLE under ICE guidance because of local device infection in whom connective tissue masses were detected in the RA/SVC immediately after the procedure. What is important, TEE at 3 months after anticoagulation and antibiotic therapy revealed that the masses remained unchanged and asymptomatic (38). The term "ghost" was introduced by Le Dolley et al. and defined as a new tubular mobile mass detected by echocardiography on the path of the lead immediately after its removal (36). The masses were found in $8 \%$ of patients undergoing TLE for infectious indications. By contrast, in the present study "ghosts" were demonstrated in patients with and without infections. A possible explanation may be that the available evidence has been obtained from TEE examinations in patients undergoing TLE due to infection. TEE in patients with noninfectious indications for lead extraction is performed only if TTE result is inconclusive, i.e., in rare cases.

Up to now, a number of studies have shown that "ghosts" have an incidence ranging from $14 \%$ to $19 \%(35,39)$. In this study, additional masses after TLE were found within the RA (19.44\%) and SVC (9.94\%). In these locations the flow of blood slows down, which is one of the conditions of the deposition of connective tissue on the leads, and promotes thrombosis due to endothelial dysregulation. Thrombi formed soon after lead implantation may undergo lysis or reorganization, causing the collagenous capsule to grow around the leads (40-42). Preoperatively, accretions (mobile connective tissue masses) were detected in $160(17.09 \%)$ cases, whereas after lead extraction there was a statistically significant increase in the incidence of intracardiac lead masses up to $33.12 \%(\mathrm{P}<0.001)$. This 

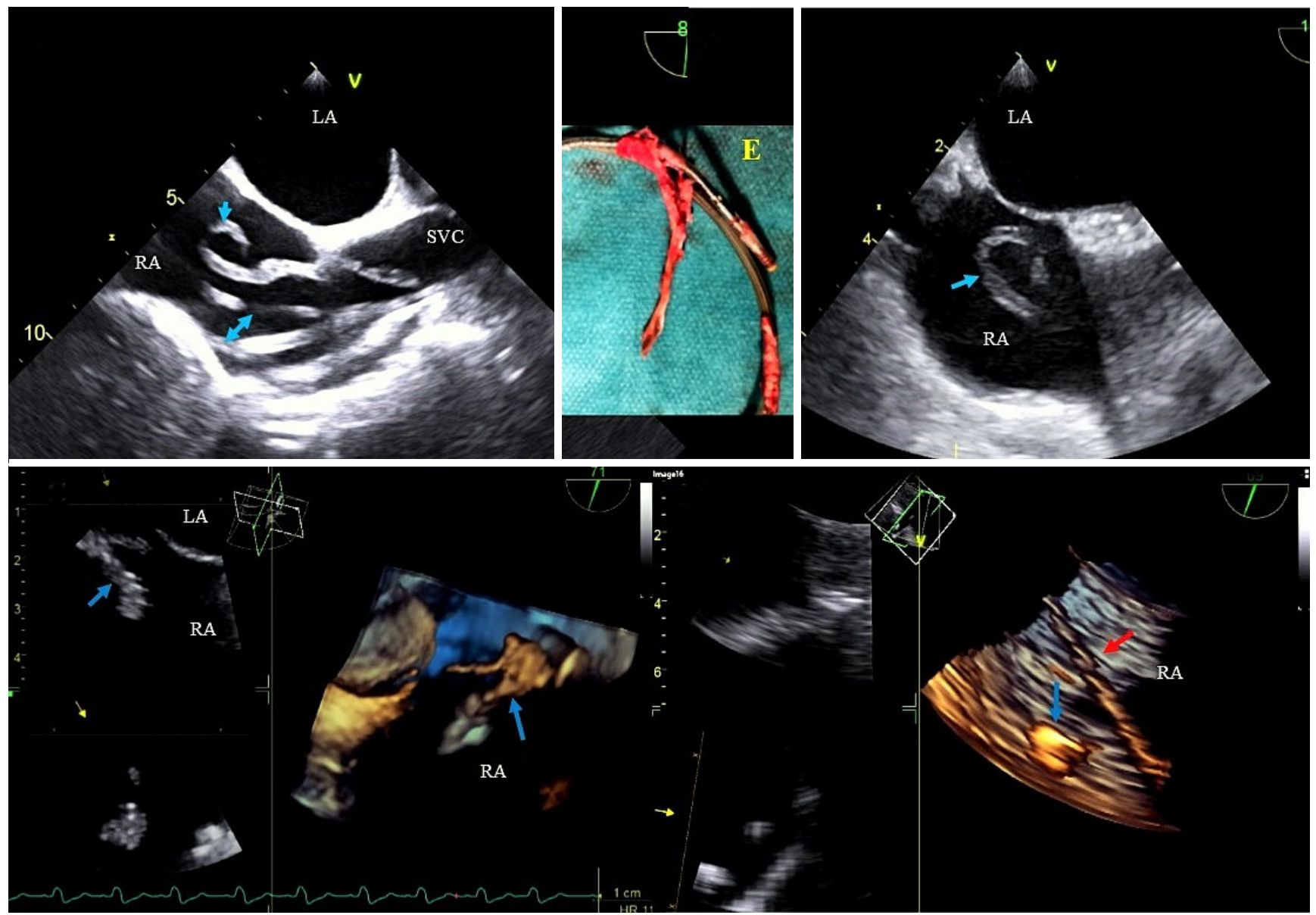

Figure 4 Residual fibrosis demonstrated in postoperative TEE (blue arrows). Red arrow: lead during extraction.

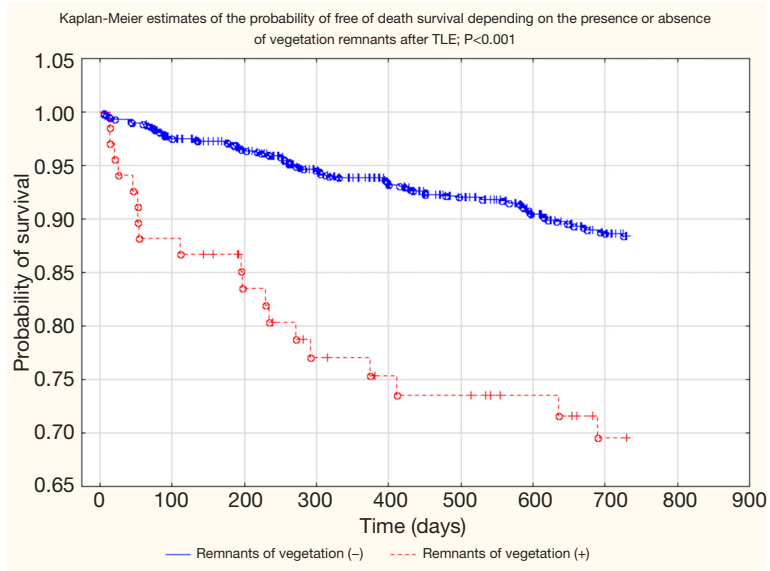

Figure 5 Kaplan-Meier estimates of the probability of free of death survival depending on the presence or absence of vegetation remnants after TLE. $\mathrm{P}<0.001$. result may be explained by partial dissection of leads from connective tissue which is also found in SVC (limitations of TEE) and the presence of so-called lead thickening and hyperechogenicity representing foci of immobile encapsulation sheaths (31) (Figure 4).

The factors that significantly increased the likelihood of residual fibrosis after TLE included multiple leads, binding sites between leads and cardiac anatomical structures and presence of asymptomatic masses on endocardial leads (AMEL) before TLE. In contrast to earlier findings (39), however, no evidence was found that residual fibrosis was significantly more frequently associated with ICD than pacemaker leads.

Clinical relevance of "ghosts" (necessity to differentiate from vegetation remnants) and their impact on long-term prognosis merits consideration. In this study "ghosts" 

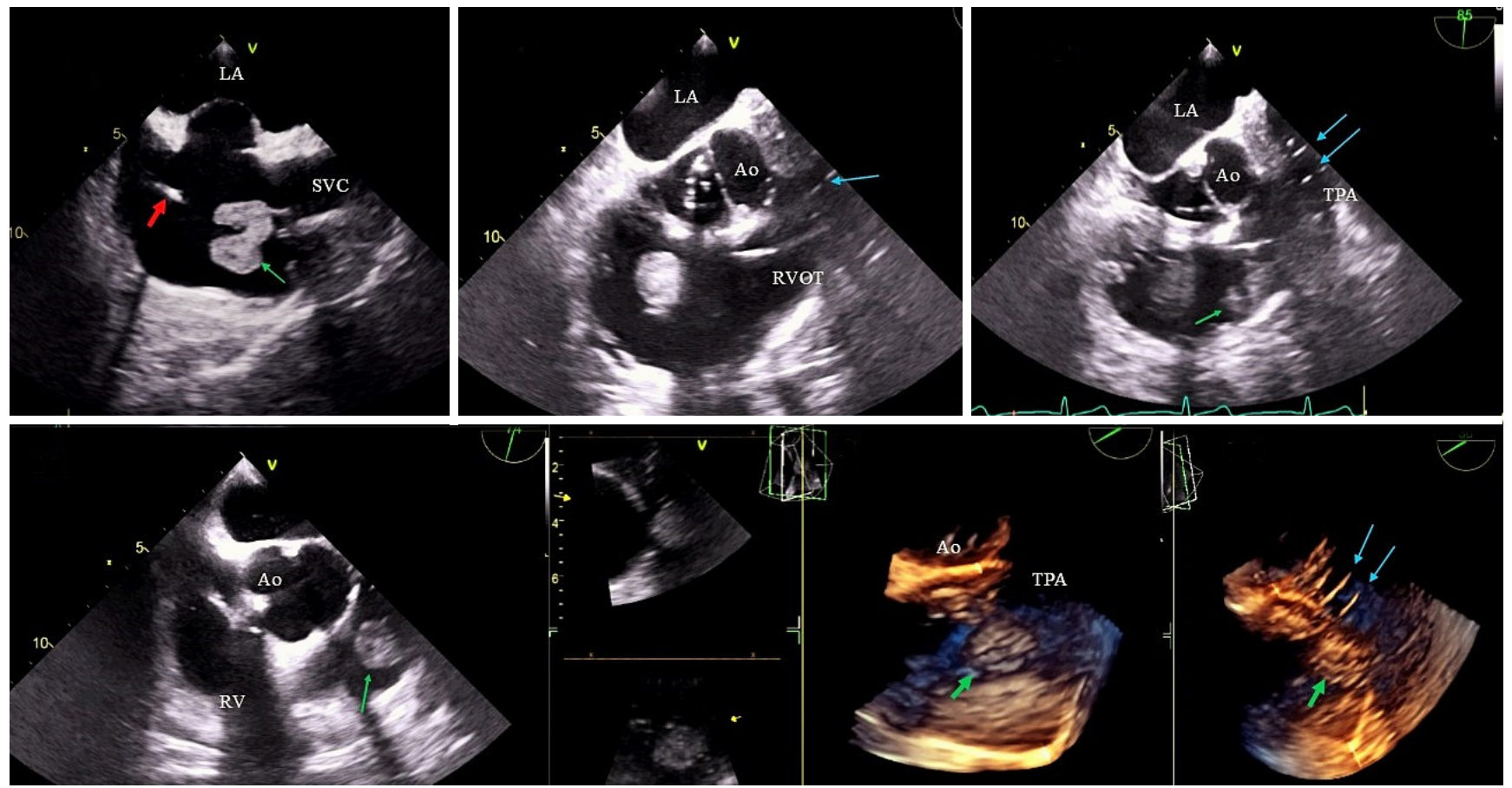

Figure 6 Embolic protection during TLE in patients at high risk of large vegetation dislodgement. Green arrows: large vegetation; red arrow: lead; blue arrows: basket in pulmonary trunk. TLE, transvenous lead extraction.

found in noninfectious patients did not affect long-term survival, whereas persistent vegetations or their fragments significantly worsened 2-year prognosis (HR $1.76,95 \%$ CI: 1.35-2.30; $\mathrm{P}=0.001$ ) (Figure 5).

Data from several studies suggest that vegetation remnants after TLE are associated with poor longterm survival $(35,43)$. In this study $58 \%$ of vegetations disappeared but $42 \%$ of them remained within the heart after the procedure. In most cases the freed pieces of vegetations dislodged into the pulmonary circulation without producing the signs of pulmonary embolism. In patients at high risk of embolization (large vegetation size) embolic protection systems were used during TLE (Figure 6).

One interesting finding in this study-reported for the first time-was that a remnant was bigger than the initial vegetation $(\mathrm{P}<0.001)$. A possible explanation for this might be that some of the vegetations on the intravenous lead route were not visualized in TEE and were displaced with a dissecting catheter towards the SVC orifice; additionally, infection that increases connective tissue buildup on the leads results in the formation of a conglomerate composed of vegetations and fibrous tissue peeled off during lead dissection (Figure 7).

From a clinical perspective it was very important to confirm the risk associated with lead abandonment detected in our previous study (44). The abandoned nonfunctional leads increased the risk of infective endocarditis $(44,45)$ and caused as high as 8-fold increase of risk of vegetation remnants after lead extraction, thus worsening prognosis and reducing chances of long-term survival.

Another very important finding in TEE after TLE is accumulation of fluid in the pericardial space. Hemorrhage to the pericardium in the course of heart wall injury during TLE is the most severe complication of the procedure occurring at a rate of $2 \%$ to $4 \%$ (1-3). TEE is a tool that precisely and immediately visualizes small amounts of fluid, changes in fluid volume and signs of tamponade that may lead to hemodynamic instability. Furthermore, this examination facilitates rapid therapeutic decision making (diagnosis of blood clotting excluding pericardiocentesis) (4-9). Risk factors for heart and wall injury during TLE are directly related to increased connective tissue proliferation. Most dangerous is fibrosis binding leads to a thin-walled RA, which is at greatest risk of injury. Other important factors are: longer lead dwell time, lead-to-lead adhesion, AMEL and higher LVEF. The higher LVEF characterizes healthier patients with potentially longer pacing time and simultaneously longer lead implant duration, which also 

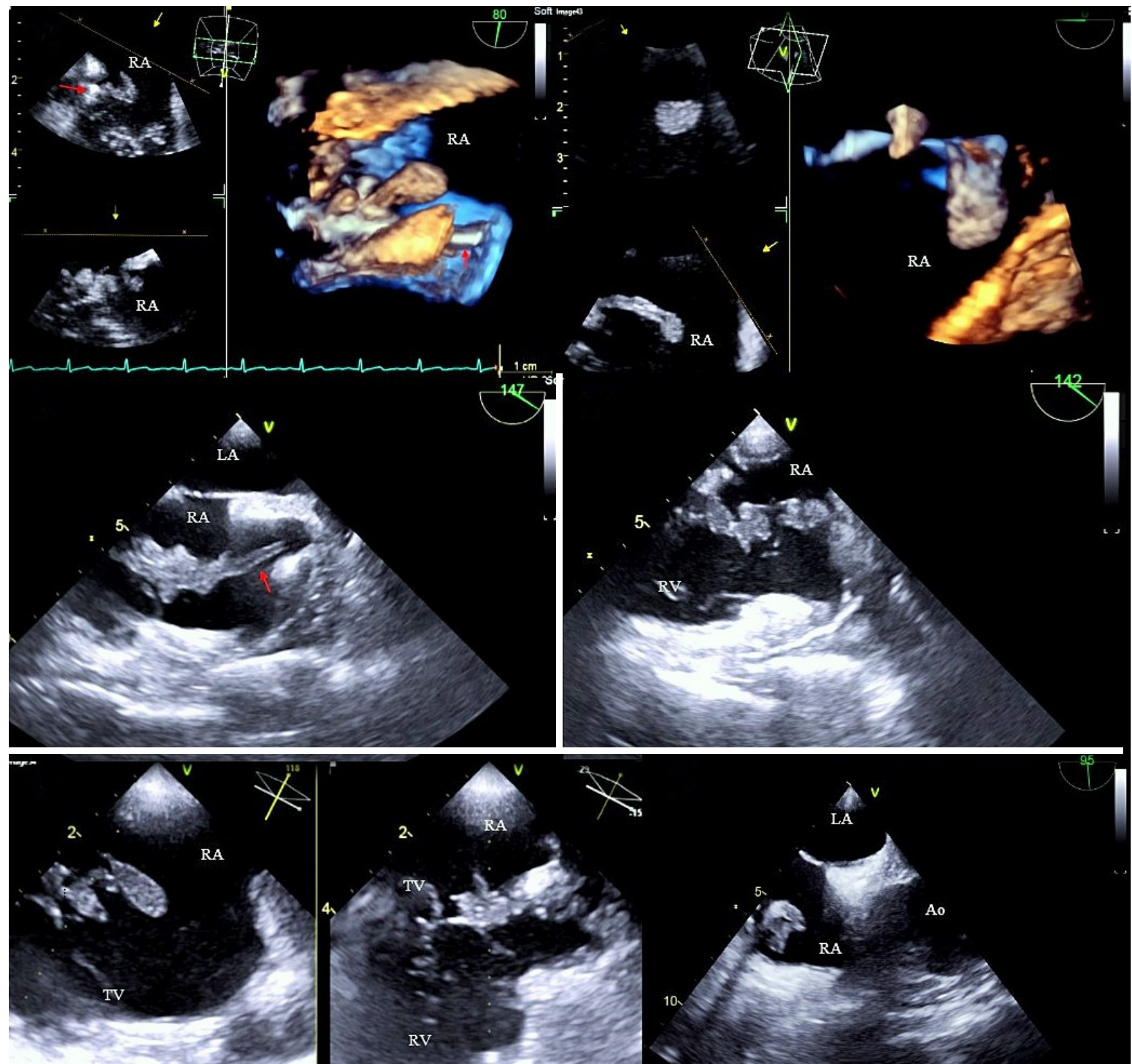

Figure 7 Vegetation remnants in postoperative TEE. Red arrows show lead before extraction. TEE, transesophageal echocardiography.

predisposes to progressive development of connective tissue. On the other hand advanced age and accompanying diseases may be protective factors in tamponade. This result is likely to be related to a shorter lead dwell time and weaker connective tissue reaction to chronically implanted leads (Figure 8).

Echocardiographic assessment after TLE includes confirmation of procedure efficacy. In this study complete procedural success meaning complete removal of the leads from cardiac cavities was achieved in $98 \%$ of patients. The complete lead removal is especially important in case of infectious indications for TLE, as retained lead fragments cause a persistent infection, thus increasing the risk of death (1-3). Fragments of broken leads or silicon tubes are relatively rarely left in the heart i.e., from $2 \%$ to $3 \%(46,47)$ (Figure 9).

In this study, $5 \%$ of leads were broken during the extraction procedure, but lead fragments were nonremovable only in $0.6 \%$ of cases (TEE confirmed no possibility of capturing the proximal lead tip embedded 


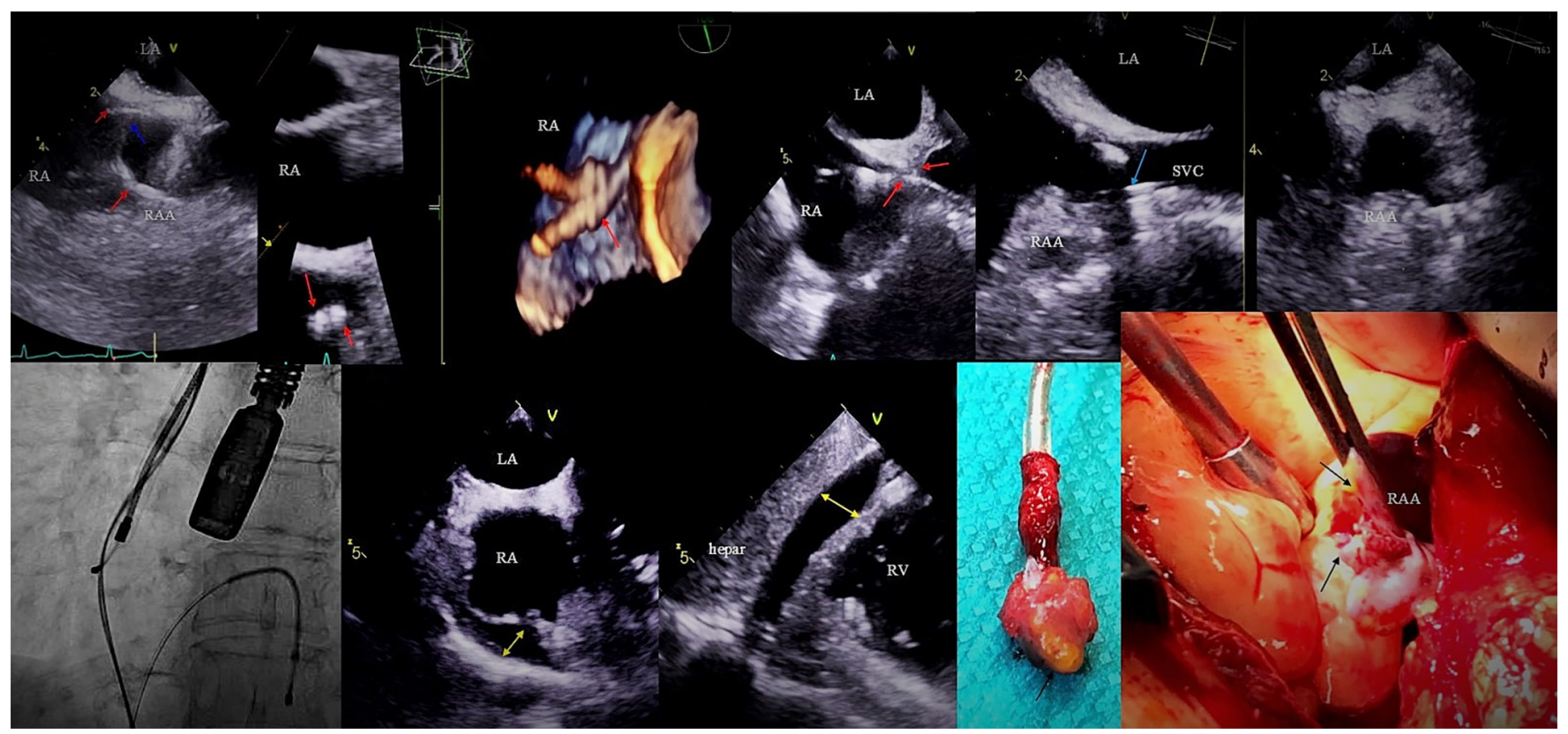

Figure 8 Extraction of 26-year-old DDD leads in a 58-year-old woman complicated with pericardial tamponade as a result of RAA perforation. Red arrows: leads; blue arrow: lead-to-lead adhesion; yellow arrow: fluid (blood) in pericardium.

in the endocardium). The strongest risk factors for lead fracture were lead-to-lead adhesions and binding sites between leads and RV $(\mathrm{P}<0.000)$ and $\mathrm{RA}(\mathrm{P}=0.042)$ as well as age of extracted leads $(\mathrm{P}=0.013)$. Several investigators have emphasized the contribution of connective tissue to increased risk of procedure difficulty and complications but so far no clear relationships have been identified $(48,49)$. The remnants of silicon tube surrounding the lead (when the lead is broken) was found incidentally i.e., in $0.7 \%$ of cases. The tube, invisible in radiological examination is detectable in TEE and for this reason it is possible to remove it and achieve complete procedural success (50).

\section{Limitations}

This is a single center observational study based on experience. The technique of TLE did not include laser energy.

\section{Conclusions}

Postoperative TEE provides additional information which is invaluable for the management of patients after TLE. Postoperative TEE results can be interpreted correctly only if compared with preoperative and intraoperative findings. The most important variables evaluated after TLE is tricuspid valve function, residual fibrosis and vegetation remnants, progression of pericardial effusion and retained lead fragments. Increment in TR after TLE occurs in $9.0 \%$ of patients, however severe TR requiring surgical repair is found only in $0.64 \%$ of patients. The likelihood of increment in TR is higher in the presence of binding sites between leads and RV, tricuspid apparatus and SVC as well as lead-to-lead adhesions before TLE. After TLE new strips of connective tissue appear along the course of the extracted lead. The predisposing factors are encapsulation sheaths before TLE and multiple extracted leads. Vegetation remnants are a frequent finding after TLE in patients with LRIE, their average size is larger as compared with initial measurements and have a negative prognostic value. Pericardial effusion occurs during or immediately after the procedure in several percent of cases, and progresses to acute cardiac tamponade in $1.3 \%$. The risk factors for acute tamponade are associated with massive proliferation of connective tissue. Lead fracture occurs during 5.3\% of extraction procedures, but lead fragments cannot be removed only in $0.6 \%$. In $0.7 \%$ silicon tube fragments are left behind but they can be removed with a lasso catheter under TEE guidance. The risk factors for lead fracture are associated with preexisting binding sites and lead-to-leadadhesions. 

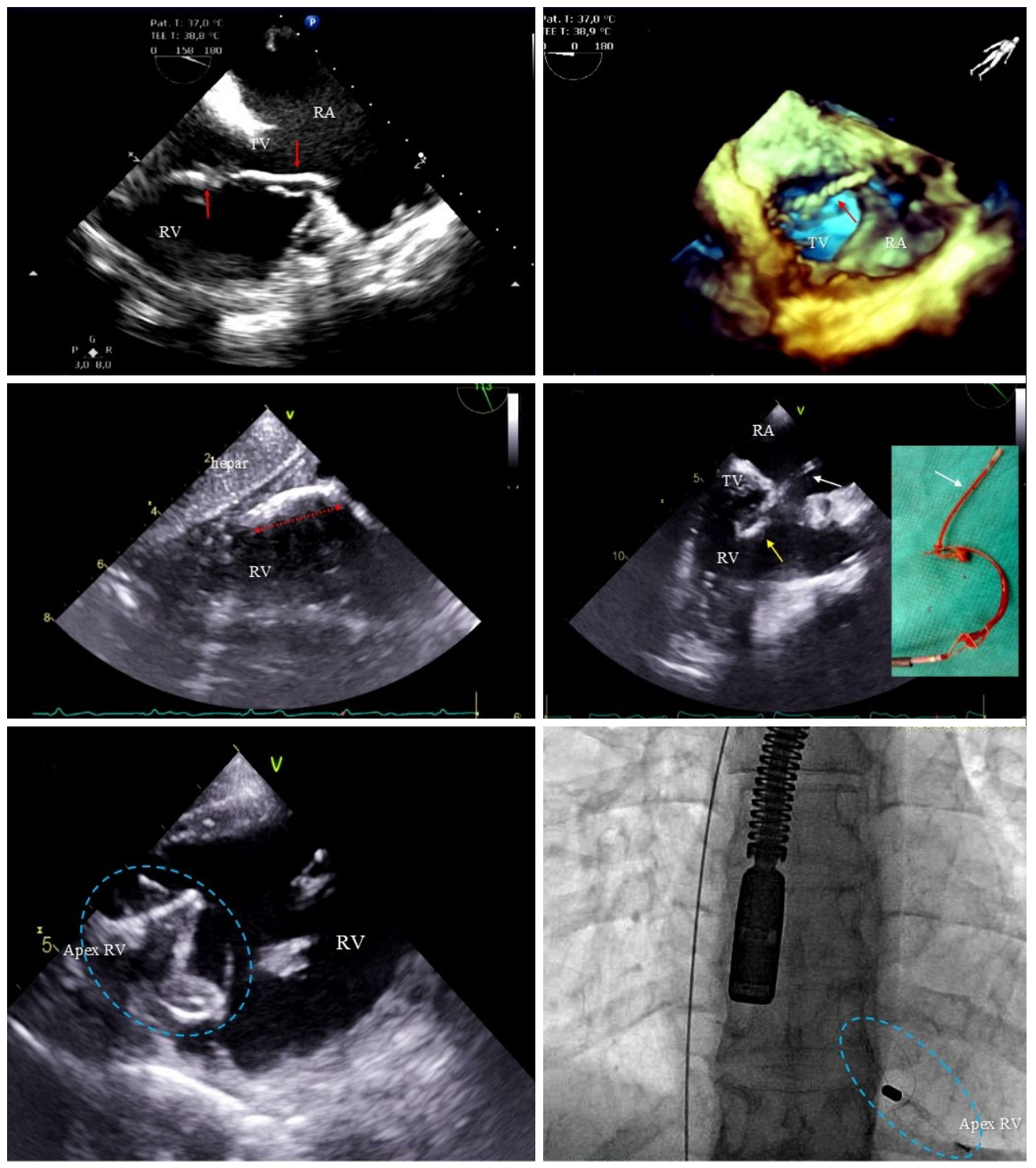

Figure 9 Fragments of leads broken during TLE and demonstrated in TEE (arrows and circles). TLE, transvenous lead extraction; TEE, transesophageal echocardiography.

\section{Acknowledgments}

Funding: None.

\section{Footnote}

Reporting Checklist: The authors have completed the MDAR reporting checklist. Available at http://dx.doi.org/10.21037/ cdt-20-871

Data Sharing Statement: Available at http://dx.doi. org/10.21037/cdt-20-871
Conflicts of Interest: All authors have completed the ICMJE uniform disclosure form (available at http://dx.doi. org/10.21037/cdt-20-871). The authors have no conflicts of interest to declare.

Ethical Statement: The authors are accountable for all aspects of the work in ensuring that questions related to the accuracy or integrity of any part of the work are appropriately investigated and resolved. The study was conducted in accordance with the Declaration of Helsinki (as revised in 2013). The study was approved by institutional 
Bioethics Committee at Regional Physicians Chamber in Lublin (No. 288/2018/KB/VII). and informed consent was taken from all the patients

Open Access Statement: This is an Open Access article distributed in accordance with the Creative Commons Attribution-NonCommercial-NoDerivs 4.0 International License (CC BY-NC-ND 4.0), which permits the noncommercial replication and distribution of the article with the strict proviso that no changes or edits are made and the original work is properly cited (including links to both the formal publication through the relevant DOI and the license). See: https://creativecommons.org/licenses/by-nc-nd/4.0/.

\section{References}

1. Kusumoto FM, Schoenfeld MH, Wilkoff BL, et al. 2017 HRS expert consensus statement on cardiovascular implantable electronic device lead management and extraction. Heart Rhythm 2017;14:e503-51.

2. Bongiorni MG, Burri H, Deharo JC, et al. 2018 EHRA expert consensus statement on lead extraction: recommendations on definitions, endpoints, research trial design, and data collection requirements for clinical scientific studies and registries: endorsed by APHRS/ HRS/LAHRS. Europace 2018;20:1217-9.

3. Wilkoff BL, Love CJ, Byrd CL, et al. Transvenous lead extraction: Heart Rhythm Society expert consensus on facilities, training, indications, and patient management: this document was endorsed by the American Heart Association (AHA). Heart Rhythm 2009;6:1085-104.

4. Nowosielecka D, Jacheć W, Polewczyk A, et al. Transesophageal Echocardiography As a Monitoring Tool During Transvenous Lead Extraction-Does It Improve Procedure Effectiveness? J Clin Med 2020;9:1382.

5. Nowosielecka D, Polewczyk A, Jacheć W, et al. A new approach to the continuous monitoring of transvenous lead extraction using transesophageal echocardiographyAnalysis of 936 procedures. Echocardiography 2020;37:601-11.

6. Strachinaru M, Kievit CM, Yap SC, et al. Multiplane/3D transesophageal echocardiography monitoring to improve the safety and outcome of complex transvenous lead extractions. Echocardiography 2019;36:980-6.

7. Hilberath JN, Burrage PS, Shernan SK, et al. Rescue transoesophageal echocardiography for refractory haemodynamic instability during transvenous lead extraction. Eur Heart J Cardiovasc Imaging 2014;15:926-32.
8. Oestreich BA, Ahlgren B, Seres T, et al. Use of Transesophageal Echocardiography to Improve the Safety of Transvenous Lead Extraction. JACC Clin Electrophysiol 2015;1:442-8.

9. Regoli F, Caputo M, Conte G, et al. Clinical utility of routine use of continuous transesophageal echocardiography monitoring during transvenous lead extraction procedure. Heart Rhythm 2015;12:313-20.

10. Dietz MF, Prihadi EA, van der Bijl P, et al. Prognostic implications of staging right heart failure in patients with significant secondary tricuspid regurgitation. JACC Heart Fail 2020;8:627-36.

11. Papageorgiou N, Falconer D, Wyeth N, et al. Effect of tricuspid regurgitation and right ventricular dysfunction on long-term mortality in patients undergoing cardiac devices implantation: $>10$-year follow-up study. nt J Cardiol 2020;15:52-6.

12. Chorin E, Rozenbaum Z, Topilsky Y, et al. Tricuspid regurgitation and long-term clinical outcomes. Eur Heart J Cardiovasc Imaging 2020;21:157-65.

13. Coffey JO, Sager SJ, Gangireddy S, et al. The impact of transvenous lead extraction on tricuspid valve function. Pacing Clin Electrophysiol 2014;37:19-24.

14. Glover BM, Watkins S, Mariani JA, et al. Prevalence of tricuspid regurgitation and pericardial effusions following pacemaker and defibrillator lead extraction. Int J Cardiol 2010;145:593-4.

15. Franceschi F, Thuny F, Giorgi R, et al. Incidence, risk factors, and outcome of traumatic tricuspid regurgitation after percutaneous ventricular lead removal. J Am Coll Cardiol 2009;53:2168-74.

16. Park SJ, Gentry JL 3rd, Varma N, et al. Transvenous Extraction of Pacemaker and Defibrillator Leads and the Risk of Tricuspid Valve Regurgitation. JACC Clin Electrophysiol 2018;4:1421-8.

17. Mehrotra D, Kejriwal NK. Tricuspid valve repair for torrential tricuspid regurgitation after permanent pacemaker lead extraction. Tex Heart Inst J 2011;38:305-7.

18. Rodriguez Y, Mesa J, Arguelles E, et al. Tricuspid insufficiency after laser lead extraction. Pacing Clin Electrophysiol 2013;36:939-44.

19. Patel B, Daraghmeh A, Machado Ch. Severe tricuspid valve regurgitation requiring surgical intervention as a result of pacemaker lead extraction: A case series. J Innov Card Rhythm Manag 2014;5:1525-9.

20. Jacheć W, Polewczyk A, Polewczyk M, et al. Transvenous Lead Extraction SAFeTY Score for Risk Stratification and Proper Patient Selection for Removal Procedures Using 
Mechanical Tools. J Clin Med 2020;9:361.

21. Al-Bawardy R, Krishnaswamy A, Bhargava M, et al. Tricuspid regurgitation in patients with pacemakers and implantable cardiac defibrillators: A Comprehensive Review. Clin Cardiol 2013;36:249-54.

22. Höke U, Auger D, Thijssen J, et al. Significant leadinduced tricuspid regurgitation is associated with poor prognosis at long-term follow-up. Heart 2014;100:960-8.

23. Cho MS, Kim J, Lee JB, et al. Incidence and predictors of moderate to severe tricuspid regurgitation after dual-chamber pacemaker implantation. Pacing Clin Electrophysiol 2019;42:85-92.

24. Delling FN, Hassan ZK, Piatkowski G, et al. Tricuspid regurgitation and mortality in patients with transvenous permanent pacemaker leads. Am J Cardiol 2016;117:988-92.

25. Chang JD, Manning WJ, Ebrille E, et al. Tricuspid valve dysfunction following pacemaker or cardioverterdefibrillator implantation. JACC 2017;69:2331-41.

26. Guigui S, Zedan A, LaPietra A, et al. Cardiovascular implantable electronic device-related tricuspid regurgitation: a multidisciplinary team approach. J Thorac Dis 2020;12:2986-9.

27. Polewczyk A, Kutarski A, Tomaszewski A, et al. Lead dependent tricuspid dysfunction: Analysis of the mechanism and management in patients referred for transvenous lead extraction. Cardiol J 2013;20:402-10.

28. Nazmul MN, Cha YM, Lin G, et al. Percutaneous pacemaker or implantable cardioverter-defibrillator lead removal in an attempt to improve symptomatic tricuspid regurgitation Europace 2013;15:409-13.

29. Montgomery JA, Ellis CR, Crossley GH. Extraction of looped transvenous pacing leads to reduce tricuspid regurgitation. Pacing Clin Electrophysiol 2017;40:644-7.

30. Bongiorni MG, Soldati E, Zucchelli G, et al. Transvenous removal of pacing and implantable cardiac defibrillating leads using single sheath mechanical dilatation and multiple venous approaches: high success rate and safety in more than 2000 leads. Eur Heart J 2008;29:2886-93.

31. Golzio PG, Errigo D, Peyracchia M, et al. Prevalence and prognosis of lead masses in patients with cardiac implantable electronic devices without infection. J Cardiovasc Med (Hagerstown) 2019;20:372-8.

32. Robinson J, Wang WYS, Kaye G. Mobile Echodensities on Intracardiac Device Leads - Is it always a cause for concern? Pacing Clin Electrophysiol 2020;43:388-93.

33. Dundar C, Tigen K, Tanalp C, et al. The prevalence of echocardiographic accretions on the leads of patients with permanent pacemakers. J Am Soc Echocardiogr
2011;24:803-7.

34. Sugrue A, DeSimone CV, Lenz CJ, et al. Mobile thrombus on cardiac implantable electronic device leads of patients undergoing cardiac ablation: incidence, management, and outcomes. J Interv Card Electrophysiol 2016;46:115-20.

35. Narducci ML, Di Monaco A, Pelargonio G, et al. Presence of 'ghosts' and mortality after transvenous lead extraction. Europace 2017;19:432-40.

36. Le Dolley Y, Thuny F, Mancini J, et al. Diagnosis of cardiac device-related infective endocarditis after device removal. JACC Cardiovasc Imaging 2010;3:673-81.

37. Bentivegna R, Cattafi G, Giannattasio C, et al. Unusual presence of 'ghosts' following lead extraction for recurrent reactive pericarditis: a case report. Eur Heart J Case Rep 2018;2:yty127.

38. Rizzello V, Dello Russo A, Casella M, et al. Residual fibrous tissue floating in the right atrium after percutaneous pacemaker lead extraction: an unusual complication early detected by intracardiac echocardiography. Int J Cardiol 2008;127:e67-8.

39. Poterała M, Kutarski A, Brzozowski W, et al. Echocardiographic assessment of residuals after transvenous intracardiac lead extraction. Int J Cardiovasc Imaging 2020;36:423-30.

40. Stokes K, Chem B, Anderson J, et al. The encapsulation of polyurethaneinsulated transvenous cardiac pacemaker leads. Cardiovasc Pathol 1995;4:163-71.

41. Candinas R, Duru F, Schneider J, et al. Postmortem analysis of encapsulation around long-term ventricular endocardial pacing leads. Mayo Clin Proc 1999;74:120-5.

42. Esposito M, Kennergren C, Holmstrom N, et al. Morphologic and immunohistochemical observations of tissues surrounding retrieved transvenous pacemaker leads. J Biomed Mater Res 2002;63:548-58.

43. Polewczyk A, Jachec W, Tomaszewski A, et al. Leadrelated infective endocarditis: Factors influencing early and long-term survival in patients undergoing transvenous lead extraction. Heart Rhythm 2017;14:43-9.

44. Jacheć W, Polewczyk A, Segreti L, et al. To abandon or not to abandon: Late consequences of pacing and ICD lead abandonment. Pacing Clin Electrophysiol 2019;42:1006-17.

45. Segreti L, Rinaldi CA, Claridge S, et al. ELECTRa Investigators. Procedural outcomes associated with transvenous lead extraction in patients with abandoned leads: an ESC-EHRA ELECTRa (European Lead Extraction ConTRolled) Registry Sub-Analysis. Europace 2019;21:645-54.

46. Wazni O, Epstein LM, Carrillo RG, et al. Lead extraction 
in the contemporary setting: the LExICon study: an observational retrospective study of consecutive laser lead extractions. J Am Coll Cardiol 2010;55:579-86.

47. Tanawuttiwat T, Cheng A, Rickard J, et al. Successful extraction of right ventricular lead remnants using the FlexCath ${ }^{\circledR}$ steerable sheath. J Interv Card Electrophysiol 2016;45:107-10

48. Poole JE, Gleva MJ, Mela T, et al. Complication rates associated with pacemaker or implantable cardioverterdefibrillator generator replacements and upgrade

Cite this article as: Nowosielecka D, Jacheć W, Polewczyk A, Kleinrok A, Tułecki Ł, Kutarski A. The prognostic value of transesophageal echocardiography after transvenous lead extraction: landscape after battle. Cardiovasc Diagn Ther 2021;11(2):394-410. doi: 10.21037/cdt-20-871 procedures: results from the REPLACE registry. Circulation 2010;122:1553-61.

49. Yakish SJ, Narula A, Foley R, et al. Superior vena cava echocardiography as a screening tool to predict cardiovascular implantable electronic device lead fibrosis. J Cardiovasc Ultrasound 2015;23:27-31.

50. Kutarski A, Chudzik M, Tomaszewski A, et al. Difficult dual-stage transcutaneous multiple lead extraction with loss of external silicone tube of broken lead. Cardiol J 2013;20:94-9. 
Postprocedural echocardiographic datacomparison with preprocedural findings (Table S1)

\section{Tricuspid valve function}

Significant/severe TR was detected in 220 (23.504\%) patients before TLE, and in $222(23.718 \%)$ patients $(\mathrm{P}=0.957)$ after the procedure. Similarly, there were no differences in mild and moderate TR before and after the procedure. Severe LDTD was confirmed in 58 patients.

After TLE the severity of regurgitation remained unaltered in $80.235 \%$ of patients. Exacerbation of TV dysfunction was observed in $85(9.081 \%)$ patients, in most cases $(n=52)$ it was a mild increment in TR. TV function improved after TLE in 100 patients $(\mathrm{P}=0.278$ as compared to increased TR by the same grade). After the procedure increment in TR by one grade was seen in 52 patients, and improvement by one grade in 90 patients $(\mathrm{P}<0.001)$. Increment in TR by 2 or 3 grades occurred in 33 patients, improvement by 2 or 3 grades in 10 patients $(\mathrm{P}<0.001)$. Severe tricuspid valve damage was detected in $6(0.641 \%)$ patients after TLE. TEE revealed that tricuspid valve damage in $12(1.389 \%)$ individuals may require surgical repair, 8 patients were selected for tricuspid valvuloplasty, including one urgent (during the same procedure). Rupture of the tendinous chords was found during 29 (3.098\%) TLE procedures (Table 2).

\section{Vegetations}

Out of 151 (16.132\%) patients with LRIE detected in preprocedural TEE 119 (78.80\% of LRIE) were diagnosed with having vegetations. The average size of the vegetation was $1.533 \pm 1.137 \mathrm{~cm}$. Lead-associated vegetations were most common being detected in 114 (75.496\% of LRIE) patients. Multiple vegetations were seen in more than half of LRIE patients $(82 ; 54.304 \%)$, in most cases they were below $2 \mathrm{~cm}$ in size (62.913\%). There were $10(6.622 \%)$ large $(2.1-3.0 \mathrm{~cm}$ in size) and $14(9.271 \%)$ very large $(>3 \mathrm{~cm}$ in size) vegetations. In the latter case special devices were used during TLE for prevention of pulmonary embolism. In case of 3 vegetations $>4 \mathrm{~cm}$ in size it was decided to carry out surgical treatment (hybrid). After lead extraction vegetation remnants were seen in cardiac cavities in 50 (33.112\% of LRIE) patients, the average size of remnants was $2.520 \pm 1.703 \mathrm{~cm}$ and was larger than at baseline $(\mathrm{P}<0.001)$. A total of 69 (45.695\% of LRIE) patients had no vegetation remnants after lead removal (Table 2).

\section{Residual fibrosis}

Overall, 549 (there were multiple manifestations in single patients) fibrous encapsulation sheaths were detected in 437 (46.688\%) patients before TLE. Adhesive interactions between leads and various anatomical structures were diagnosed in $236(25.213 \%)$ patients, binding to right atrial (RA) wall in 65 (6.944\%), to superior vena cava (SVC) in $56(5.983 \%)$, and lead-to-lead adhesions in $172(18.376 \%)$ patients (Table 2).

After TLE residual fibrosis was found in 310 patients, being almost twice as frequent as before TLE. Floating connecting tissue scar was detected as a single focus in $219(23.39 \%)$ patients, multiple foci in $91(9.722 \%)$. Their average length and width were $21.015 \pm 15.446$ and $4.411 \pm 1.590 \mathrm{~mm}$, respectively. They were most often found in RA $(182 ; 19.444 \%)$ and SVC $(93 ; 9.935 \%)$, less often in RV (61; 6.517\%), on the tricuspid apparatus (46; 4.914\%), incidentally in CS. Floating connecting tissue scar was found at more than one site in $8.653 \%$ of patients (Table 2).

\section{Pericardial effusion}

Preoperatively, pericardial effusion was found in $54(5.770 \%)$ patients, including $40(4.274 \%)$ with "wet" perforation, mainly of the RV wall. In 151 (16.132\%) patients perforation was "dry" i.e., the tip of the lead was beyond the RV wall contour without signs of fluid in the pericardium, sometimes with a pericardial reaction and a drop of fluid near the lead tip. A total of $34(3.632 \%)$ patients were monitored for the presence of effusion, including $12(1.282 \%)$ with signs of tamponade during or after TLE (Table 2).

\section{Retained lead fragments}

The lead was broken during $50(5.342 \%)$ extraction procedures, in $6(0.641 \%)$ cases the lead fragment could not be removed, in the remaining $44(4.701 \%)$ procedures pieces of the lead were successfully extracted using additional tools (lassos and sheaths). In 7 (0.0749\%) cases there were fragments of silicon tube demonstrable only in TEE (invisible under fluoroscopy), which in 5 patients were removed transvenously, in the remaining two patients during operations for other reasons (Table 2). 


\begin{tabular}{|c|c|c|c|}
\hline TEE findings & ${ }^{*}$ Before TLE & ${ }^{*}$ After TLE & $\begin{array}{l}\text { Wilcoxon paired test, } \\
\chi^{2} \text { test }\end{array}$ \\
\hline $\mathrm{TR}(0-\mathrm{IV})$, mean $\pm \mathrm{SD}$ & *1.689 \pm 1.009 & *1.708 \pm 0.991 & 0.959 \\
\hline TR absent/ mild (0-I), n (\%) & *543 (58.013) & *541 (57.799) & 0.963 \\
\hline TR moderate (II), $\mathrm{n}(\%) / \mathrm{LDTD}, \mathrm{n}$ & *173 (18.483)/2 & *173 (18.438) & 1.000 \\
\hline TR significant/severe (III-IV), n (\%)/LDTD, n (\%) & *220 (23.504)/58 & *222 (23.718) & 0.957 \\
\hline \multicolumn{4}{|l|}{ Tricuspid regurgitation change after TLE } \\
\hline TR without change after TLE, $n(\%)$ & & $751(80.235)$ & \\
\hline TR change after TLE $(+1)$ vs. $(-1), \mathrm{n}(\%)$ & $52(5.556)$ & $90(9.615)$ & 0.001 \\
\hline TR change after TLE (+2 or 3$)$ vs. ( -2 or 3$), \mathrm{n}(\%)$ & $33(3.526)$ & $10(1.068)$ & 0.001 \\
\hline TR change (all) (+) vs. (-), $\mathrm{n}(\%)$ & $85(9.081)$ & $100(10.684)$ & 0.278 \\
\hline \multicolumn{4}{|l|}{ TLE-associated damage to tricuspid valve apparatus } \\
\hline Increment in TR after TLE by 2 degrees, $\mathrm{n}(\%)$ & NA & $33(3.526)$ & \\
\hline Increment in TR after TLE by 2 degrees to IV degree, $\mathrm{n}(\%)$ & NA & $6(0.640)$ & \\
\hline Damage to tendinous chords, $\mathrm{n}(\%)$ & NA & $29(3.098)$ & \\
\hline Flail tricuspid leaflet initially requiring intervention after TLE, $n(\%)$ & NA & $12(1.389)$ & \\
\hline \multicolumn{4}{|l|}{ Vegetations } \\
\hline Presence of vegetations (TTE or and TEE), $n$ (\%) & *119 (12.714) & *50 (5.342) & $P<0.001$ \\
\hline Max. diameter of vegetation (if present) mean \pm SD & *1.533 \pm 1.137 & *2.520 \pm 1.703 & $P<0.001$ \\
\hline Presence of vegetations $<2 \mathrm{~cm}, \mathrm{n}(\%)$ & *95 (10.150) & *37 (3.953) & 0.261 \\
\hline Presence of vegetations $>2 \mathrm{~cm}, \mathrm{n}(\%)$ & *24 (2.564) & *13 (1.389) & 0.261 \\
\hline Single vegetation, $\mathrm{n}(\%)$ & *37 (3.953) & *45 (4.808) & $P<0.001$ \\
\hline Multiple vegetations, $\mathrm{n}(\%)$ & *82 (8.761) & *5 (0.534) & $\mathrm{P}<0.001$ \\
\hline Vegetations associated with leads, $\mathrm{n}(\%)$ & *114 (12.179) & NA & \\
\hline Vegetations not associated with leads, $\mathrm{n}(\%)$ & *3 $(0.321)$ & *4 (0.427) & 1.000 \\
\hline Vegetations associated with leads and heart structures, $n(\%)$ & *2 (0.214) & NA & \\
\hline \multicolumn{4}{|l|}{ Tissue scars-AMEL, 549 (58.654\%) in 437 patients } \\
\hline Lead thickening, $\mathrm{n}(\%)$ & $277(29.594)$ & NA & \\
\hline Clot on the lead, $\mathrm{n}(\%)$ & $75(8.013)$ & NA & \\
\hline Vegetation-like masses, n (\%) & $37(3.953)$ & NA & \\
\hline Fibrous tissue encasing the lead/floating connecting tissue scars, n (\%) & $160(17.094)$ & $310(33.120)$ & $P<0.001$ \\
\hline Single floating connective tissue scars after TLE, $\mathrm{n}(\%)$ & NA & $219(23.397)$ & \\
\hline Multiple floating connective tissue scars after TLE, $n(\%)$ & NA & $91(9.722)$ & \\
\hline Average length of floating connective tissue scars after TLE, mean \pm SD & NA & $21.015 \pm 15.446$ & \\
\hline Average width of floating connective tissue scars after TLE, mean \pm SD & NA & $4.411 \pm 1.590$ & \\
\hline
\end{tabular}

Fibrous tissue binding the lead to the superior vena cava and heart structures

Fibrous tissue binding the lead to the SVC, $n(\%)$

$\begin{array}{cc}56(5.983) & \text { NA } \\ 65(6.944) & \text { NA } \\ 90(9.615) & \text { NA } \\ 106(11.325) & \text { NA } \\ 172(18.377) & \text { NA }\end{array}$

Fibrous tissue binding the lead to the heart structures (all), $\mathrm{n}(\%)$

Fibrous tissue binding the lead to the RV wall, $\mathrm{n}$ (\%)

Lead-to-lead adhesion

$172(18.377) \quad$ NA

Pericardial fluid after or during TLE

Appearance of fluid during TLE causing cardiac tamponade (complication), $\mathrm{n}$ (\%)

Appearance of fluid during TLE without hemodynamic disturbances (clinically asymptomatic), $\mathrm{n}(\%)$

Pericardial fluid surrounding the tip as a symptom of "wet" cardiac wall perforation during TLE, $\mathrm{n}$ (\%)

Asymptomatic pericardial fluid before and after TLE not caused by TLE or lead perforation, $\mathrm{n}(\%)$

$\begin{array}{ll}\text { NA } & 12(1.282) \\ \text { NA } & 22(2.350)\end{array}$

$40(4.274) \quad$ NA

$14(1.496) \quad$ NA

Lead fracture

Lead fracture during extraction

Broken lead insulation with successful extraction

Broken lead with unsuccessful extraction of metal remnant

NA $\quad 7(0.749)$

NA $\quad 6(0.641)$

AMEL, asymptomatic masses on endocardial leads; LDTD, lead-dependent tricuspid dysfunction; RA, right atrium; RV, right ventricle; SVC, superior vena cava; TEE, transesophageal echocardiography; TLE, transvenous lead extraction; TR, tricuspid regurgitation; TTE, transthoracic echocardiography. 